A comissão examinadora estava presidida pelo diretor da Faculdade, prof. José Salgado Martins, e era compostá pelos professôres Jobim Meirelles.

A tese - "O corporativismo no campo da Economia" - foi defen-
ida durante cinco horas, esgotando-se o tempo regulament dida durante cinco horas, esgotando-se o tempo regulamentar. A prova foi relativa ao ponto "Populacão econômica do transporte" e a didática 0 dr. Mem de Sá conquistou emigração e imigração".

\title{
CONGRESSO JURÍDICO
}

Para comemorar o cinqüentenário da Faculdade de Direito, assim como o centenário do Código Comercial, a direção da Faculdade decidiu realizar um congresso juridico.

O certame, que contará com a colaboração e a presença de notáveis juristas do continente, será instalado no dia 11 de agôsto, data aniversária da instituição dos cursos jurídicos no Brasil.

E' o seguinte o

\section{TEMÁRIO DO CONGRESSO}

- Direito Mercantil -

1. ${ }^{\mathrm{a}}$ PARTE

Estudos sôbre o Código de 1850

ORIENTACÃO QUE PRESIDIU A FEITURA DO CÓDIGO COMERCIAL DE 1850 :

a) quanto à concepção político-jurídica da disciplina

b) quanto à técnica legislativa;

c) quanto ao critério de delimitação da matéria.

2. O DIREITO COMERGIAL BRASILEIRO CONSUETUDINÁRIO NA CENTÚRIA DE 1850 A 1950 :

a) das realizacõos da prática contratual

d) da elaboração da doutrina;

c) das aquisições da jurisprudência.

3. SENTIDO DA LEGISLACÃO SUPERVENIENTE, INTEGRADORA E DERROGATÓRIA DO CÓDIGO:

a) as idéias gerais dêste;

b) a concepcão político-jurídica da disciplina;

c) a delimitação da matéria considerada mercantil;

d) a técnica legislativa.

4. CARACTERES GERAIS DO DIREITO COMERCIAL BRASILEIRO VIGENTE: 


\section{2. ${ }^{\mathrm{a}}$ PARTE}

Estudos para o futuro Código Comercial

5. AS TENTATIVAS DE REFORMA DO CóDIGO DE 1850:

a) apreciação sôbre os diversos projetos, anteprojetos, esboços e sugestões

b) seleção e sistematização do material aproveitável.

\section{DIVISÃO DAS SECCÕES:}

1. Seccão: Direito Romano, Direito Canônico e História do Direito.

2. Secção: Direito Civil, Direito Civil Comparado e Direito Internacional Privado.

3. Secção: Direito Mercantil e Direito Mercantil Comparado.

4. Secção: Direito Penal, Criminologia e Medicina Legal.

5. Secção: Direito Judiciário Civil e Direito Judiciário Penal.

6. Seç̧ão: Teoria Geral do Estado, Direito Internacional Público, Direito Constitucional e Direito Administrativo.

7. Secção: Introdução - Ciência do Direito e Filosofia do Direito.

8. Secção: Economia Politica, Ciência das Finanças e Ciência da Administração.

9. Secção: Direito Industrial e Direito do Trabalho.

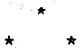

RELAÇÃO DOS BACHARELANDOS DO ANO DE 1950

Achiles Brandão Loureiro

Arthur Augusto Itaquy F.

Antonio Carlos Elizalde

Aytonio de Almeida Martins Costa Neto

Antonio de Almeida Tubino Ardaiz

Bruno Dockhorn

Bonorino Butelli

Bruno Galhardo de Mendonça Lima

Carlos Luiz Poils

Clemente Goncalves de Oliveira F.

Carlos Alberto Mondadori

Carlos Ignacio Sant'Anna

Claudio Jacobus Furtado

Darcy Dreon

Ernani Graeff

Eloy Schneider

Ernani Magalhães Machado

Enio Gualdi

Enio Godoy Moraes

- Edgar Pedro Jacob Grin

Ernani Seabra de Souza

Fernando Bruno de Carvalho Degrazia

Fabio Brito de Azambuja

Gabriel Silveira Abbott

Justo José Galves F.o

João Francisco Diehl
José Schmidt Silveira

José Albite Silva

João Antonio de Souza Mascarenhas

Jorge Abel Neto

Justino Albuquerque de Vasconcellos

Jayme Brum Brigido Madaleno

João Abichequer

Joaquim Ellam. Salles Perdomo

José Candido dos Santos

Jorge Vasconcellos Muniz

Jorge Alberto Medaglia Muccillo

João Avelino Schuster

Julio Marques Guimarães

Julinha Zoraide Feijó

José Alvares da Fontoura

José Alvares da Fonto

Laureano Jose Cortera Mariano da Rocha

Luiz Pericles Fontoura Alves

Lucia Martins Costa A

Maria da Graça Co Oliveira Pianca

Manoel Burd

Ney da Gama Ahrends

Ney da Rosa Goulart

Nelson Cavalcanti de Albuquerque

Nely Alt da Rocha

Nicolau Angelo Viceconti

Nelson Cardoso da Silva

Ney Sá

Ney Sá Silveira dos Santos

Olavo José Munari

Olavo Jose Munari

Oscar Alves da S

Octacilio Schüler

Octavio Badui Germano

Osmar Lopes da Cunha

Percy Vieira Stumpf

Paulo Germano João

Paulo Rosa Waihrich

Rugero Ravizzoni

Ruy Teixeira

Sylo Soares

Sylo Soares

Sidy Orsini

Wiegbert Saft

Wanderley Collaceo Veras

José Paes Pinto 